\title{
Ambulatory blood pressure monitoring in children suffering from orthostatic hypertension
}

\author{
Yang Zhixiang ${ }^{1}$, Wang Cheng ${ }^{2}$, Xiang Jibing ${ }^{1}$, Ge Bisheng ${ }^{1}, \mathrm{Xu} \mathrm{Ming}^{1}$ and Liu Deyu${ }^{1 *}$
}

\author{
*Correspondence: \\ Ix_Idy@163.com \\ 1 Department of Pediatrics, \\ Lixian People's Hospital \\ in Hunan, Lixian 415500, \\ China \\ Full list of author information \\ is available at the end of the \\ article
}

\begin{abstract}
Background: It is particularly important to utilize appropriate blood pressure measurement methods to evaluate the changes of orthostatic hypertension $(\mathrm{OHT})$ for children, and this study was designed to analyze the blood pressure type in OHT children with $24 \mathrm{~h}$ semiautomatic ambulatory blood pressure monitoring.

Methods: Children who were diagnosed by head-up tilt table test as OHT patients (OHT group) and treated or hospitalized in the syncope specialist outpatient unit of the Second Xiangya Hospital of Central South University mainly for syncope or presyncope with unknown causes during the October, 2009 to September, 2013 were recruited in the study. Healthy children that came to the hospital for physical examination at the same time period according to age and sex were matched as control group. Semiautomatic ambulatory blood pressure monitoring of every child was recorded. The differences of daytime systolic (diastolic) pressure and night systolic (diastolic) pressure were calculated, and the average systolic pressure and diastolic pressure of the entire day, daytime and night were also calculated, respectively.

Results: There were 23 boys and 17 girls in OHT group, aging (11.5 \pm 1.9$)$ years. There were 22 boys and 18 girls in the control group, aged (10.6 \pm 2.4$)$ years. The difference of daytime systolic pressure and night systolic pressure of the control group was higher than that of OHT group, while the average systolic pressure of the whole day, the average diastolic pressure of the whole day, the daytime average systolic pressure, the daytime average diastolic pressure, the night average systolic pressure and the night average diastolic pressure were higher than that of the control group $(P>0.05)$. The difference of daytime diastolic pressure and night diastolic pressure of the control group was higher than that of OHT group (P>0.05). Most children of the OTH group had non-dipper blood pressure type (72.5\%), while most children of the control group had a dipper blood pressure type (55.0\%). In addition, the time domain SDNN and SDANN in the OHT group were higher than those in the control group $(P<0.01)$. And, the indicators including TP, ULF, VLF, and LF/HF were higher in the OHT group, when compared with control group $(P<0.01)$. Besides, in terms of subgroup analysis within the OHT group, the age difference between boys and girls was not statistically significant $(P>0.05)$. When compared with grils, the time domain SDNN increased $(P=0.003)$, and the frequency index TP, ULF, and VLF increased in boy group $(P<0.05)$.
\end{abstract}

Conclusion: OHT Children's autonomic nervous system showed dysfunction, and differences of systolic blood pressure between day and night were much lower than 
those of healthy children, and the main blood type was non-dipper blood pressure with circadian rhythm disappearing.

Keywords: Semiautomatic ambulatory blood pressure monitoring, Children, Orthostatic hypertension

\section{Background}

To our best knowledge, orthostatic hypertension (OHT) refers to normal blood pressure (BP) in the supine position, and suddenly raised blood pressure when standing or sitting [1]. As known to all, the normal BP is defined as systolic BP (SBP) less than $140 \mathrm{mmHg}$ and diastolic BP (DBP) more than $90 \mathrm{mmHg}$ at three consecutive consultations. And, OHT is defined as a drop of SBP less than $20 \mathrm{mmHg}$ and/or DBP less than $10 \mathrm{mmHg}$ at orthostasis [2]. It is noted that the BP should be assessed after 1 and 2 min of standing from a supine position. With respect to the physiological mechanism of OHT, it is an over-reacting of the sympathetic nervous system, involving a hypersensitivity of vascular baroreceptors in response to orthostasis [3-5]. As far as we are concerned, OHT has potential risk to induce cerebrovascular events and sustained arterial hypertension. According to previous publications, the relevant studies concentrating on OHT mostly focused on the elderly population [6]. Additionally, it is also involved in young and middle-aged people, but rarely reported in children. Concerning the incidence rate of OHT, there is no unified conclusion. In early 1992, Rutan et al. indicated that the incidence rate of OHT in healthy pilots was 4.2\% [7]. In 2012, Wang Lili et al. reported that the incidence rate of OHT in elderly patients with hypertension was 9.0\% [8]. In 2012, Chinese scholar Du Junbao proposed the diagnostic criteria of OHT in children, and analyzed their clinical features [9]. According to this diagnostic criteria, in 2013, Kang et al. analyzed the clinical information of children $(n=2089$, age range 2.0-17.9) with syncope, headache, dizziness, chest tightness, and sigh. And the data illustrated that the total detection rate of OHT was $23.8 \%$, males were higher than females $(25.9 \%$ versus $21.6 \%, \mathrm{P}<0.05)$, 12-year-old group higher than $<12$-year-old group (28.1\% versus $20.5 \%, \mathrm{P}<0.01)$ [10]. Additionally, OHT is closely associated with the occurrence and development of persistent hypertension, cardiovascular events, diabetes, chronic kidney disease, asymptomatic cerebral infarction, and deep white matter ischemic lesions [11]. Therefore, it is particularly important to utilize appropriate blood pressure measurement methods to evaluate the changes of OHT. The 24-h semiautomatic ambulatory blood pressure monitoring can fully reflect the 24-h blood pressure changes and circadian rhythm of subjects, and it is an effective tool for objectively evaluating blood pressure changes. This technique can reduce the measuring error in traditional BP measurement methods, and avoid the influence of "white coat effect" [12]. According to the Consensus of Adolescent Children issued by the American Heart Association in 2014, the 24-h semiautomatic ambulatory blood pressure monitoring is effective in the diagnosis of white coat hypertension, asymptomatic hypertension, prehypertension, isolated diastolic hypertension, and nocturnal hypertension [13]. At present, there are few reports at home and abroad about the application of 24-h semiautomatic ambulatory blood pressure monitoring to evaluate the OHT type in children. In this case-control study, the 24-h semiautomatic ambulatory blood pressure monitoring was utilized 
to analyze OHT types in the Second Xiangya Hospital of Central South University, which provided reference for the diurnal blood pressure change of OHT in children.

\section{Methods}

\section{OHT diagnostic criteria of the identified children}

The normal blood pressure measured $10 \mathrm{~min}$ after supine in a quiet environment is considered to be basal blood pressure. And the OHT changes were measured 3 min after upright tilt test (HUTT, tilt angle 60). If the systolic blood pressure increased $\geq 20 \mathrm{mmHg}$, and (or) the diastolic blood pressure increased $\geq 10 \mathrm{mmHg}$ $(1 \mathrm{mmHg}=0.133 \mathrm{kPa})$, when compared with basal blood pressure, the patients could be diagnosed with OHT [9].

\section{Inclusion and exclusion criteria of $\mathrm{OHT}$}

(1) From October 2009 to September 2013, children at the syncope clinic of our hospital, or hospitalized children with unexplained syncope and premonitory syncope. (2) Patients were diagnosed with OHT via HUTT. (3) Physical examination, blood biochemical examination (fasting blood glucose, myocardial enzyme), conventional electrocardiogram, Holter electrocardiogram, echocardiography, electroencephalogram, cranial $\mathrm{CT}$ and MRI were carried out, in order to exclude heart, lung, brain, kidney and thoracic wall diseases.

\section{Study design}

In the same period, healthy children in the Children's Health Clinic of Xiangya Second Hospital of Central South University were selected into this research, and were matched with the OHT group (one-to-one based on age and sex). The identified patients were divided into two groups, and received basic HUTT (BHUT) and sublingual nitroglycerin tilt test (SNHUT), respectively. The electric tilting bed (ST-711) manufactured by Beijing Juchi Medical Technology Co., Ltd. and the tilting test monitoring software system (SHUT-100) provided by Beijing STADLEY Technology Inc. were utilized in this study. The specific inspection method refers to the guidelines for children's syncope diagnosis issued by the Chinese Medical Association [14].

\section{Semiautomatic ambulatory blood pressure monitoring}

During the semiautomatic ambulatory blood pressure monitoring examination, the subjects were home at $24 \mathrm{~h}$. The ABPM 6100 monitor is provided by Welch Allyn in America, and the detailed information is as follows. (1) Select the same wide cuff and the same arm as semiautomatic ambulatory blood pressure monitoring. (2) Use a mercury sphygmomanometer to measure BP for 2 times, and then record BP value. (3) Initialize the BP monitoring and then enter the subject's personal information. (4) The subjects were required to normatively wear BP monitoring, and manually measure blood pressure for 1 or 2 times. If the difference of systolic blood pressure between mercury sphygmomanometer and electronic sphygmomanometer less than $5 \mathrm{mmHg}$, the electronic sphygmomanometer could be considered to meet the requirements. Meanwhile, explain to the participants the precautions of wearing BP monitoring, and remind the required work and rest time. (5) After semiautomatic ambulatory blood pressure monitoring for $24 \mathrm{~h}$, the blood pressure 
information of the subjects was input into the computer [15]. (6) Referring to the revised semiautomatic ambulatory blood pressure monitoring criteria for healthy children in 1997, the ambulatory blood pressure data can be achieved [16]. In this study, 6:00 to 22:00 was set as the daytime awakening time, and 22:00 to 6:00 in the next day was set as the nighttime sleep time. The blood pressure was monitored once every $30 \mathrm{~min}$ during the day and night, and the total monitoring time was not less than $23 \mathrm{~h}$ throughout the day. The BP judgment standard refers to the authoritative literature [17]. If the number of effective blood pressure less than $80 \%$, it must be repeated every other day. In terms of matters needing attention, choose non-dominant arm to receive BP measuring. Secondly, determine cuff size based on the subject's upper arm circumference. Thirdly, when the semiautomatic ambulatory blood pressure monitoring automatically measures BP, the upper arm of the cuff should be kept as static as possible. Fourthly, during semiautomatic ambulatory blood pressure monitoring, should avoid bathing, agitation, anxiety, strenuous exercise, and ban drinking and other diets that affect autonomic function. Fifthly, during BP monitoring, children's daily routines and activities should be recorded, such as when they wake up, sleep, and take activities. At last, the subjects cannot stop BP monitoring at will [18]. Besides, the parameters of semiautomatic ambulatory blood pressure monitoring are as follows. (1) Average systolic BP $($ diastolic BP $)=$ total value of systolic or diastolic BP in each time period/number of measuring times during each period. Calculate the mean systolic and diastolic BP at $24 \mathrm{~h}$, in the daytime, and in the nighttime. (2) Diurnal variation of systolic BP $=$ (mean systolic BP in the daytime - mean systolic BP in the nighttime)/mean systolic BP in the daytime $\times 100 \%$. (3) Diurnal variation of diastolic $\mathrm{BP}=$ (mean diastolic $\mathrm{BP}$ in the daytime - mean diastolic $\mathrm{BP}$ in the nighttime)/mean diastolic BP in the daytime $\times 100 \%$.

\section{Types of blood pressure}

When concerning the types of blood pressure, the thorough explanations are as follows. Under normal circumstances, the human body's BP rises throughout the day and falls during the night, which can be described as "long handle spoon" curve [19]. (1) Dipper BP: Nocturnal BP drop $>10 \%$, when compared with daytime BP, as shown in Fig. 1a. (2) Nondipper BP: Nocturnal BP drop < 10\%, when compared with daytime BP, as shown in Fig. 1b. (3) Over spoon-shaped BP: Nocturnal BP drop $>20 \%$, when compared with daytime BP, as shown in Fig. 1c. (4) Inverse spoon-shaped BP: Nocturnal BP does not drop or increase, as shown in Fig. 1d.

\section{Statistical analysis}

The statistical analysis was done by SPSS 21.0 Software. Quantitative variables were illustrated as mean $\pm \mathrm{SD}$, the comparisons between groups were carried out via independent sample $t$ test. The qualitative variables as percentages, and the comparisons between groups were conducted with Chi square test. $\mathrm{P}<0.05$ was considered statistically significant.

\section{Results}

\section{General characteristics of the identified patients}

40 cases in OHT group, 23 boys and 17 girls, age varied from 7 to 14 years old, mean age $11.5 \pm 1.9$ years old. 40 patients in the control group, 22 boys and 18 girls, age ranged from 4 to 14 years old, mean age $10.6 \pm 2.4$ years old. There was no significant differences 

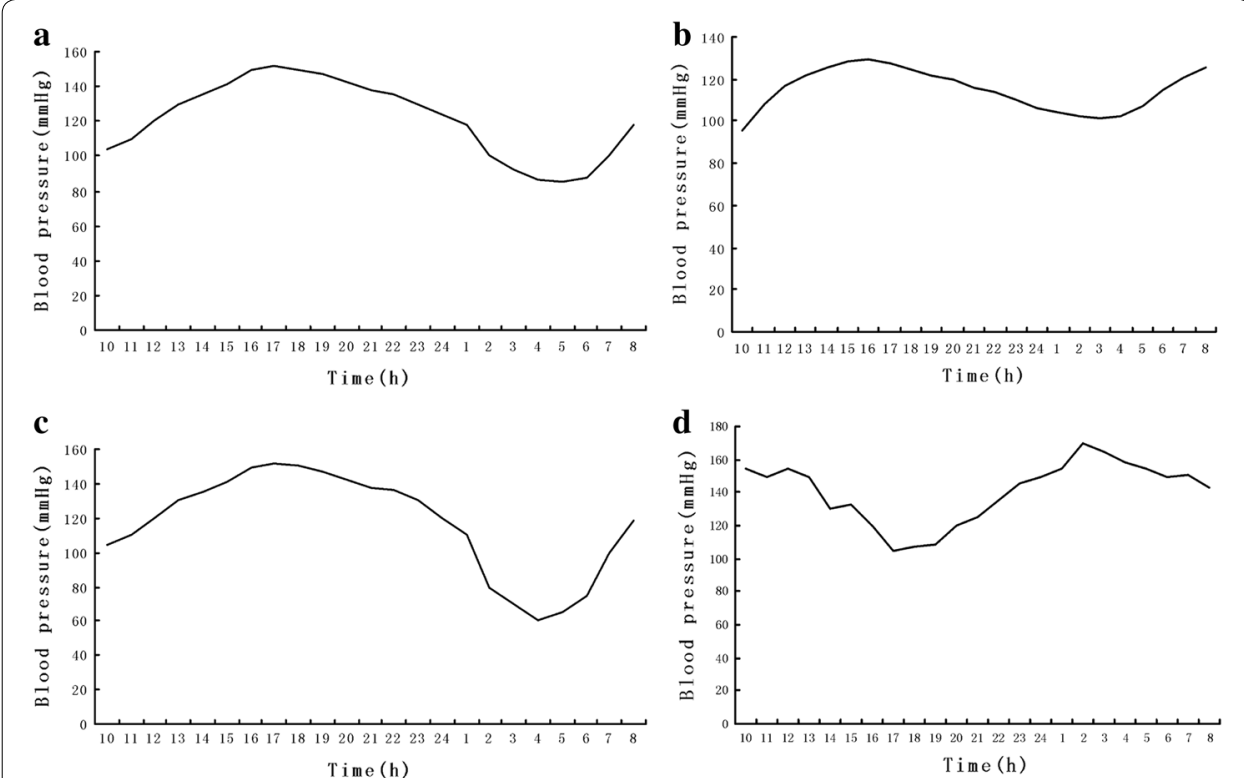

Fig. 1 Diagram of blood pressure type. a Dipper blood pressure; b non-dipper blood pressure; c over spoon-shaped blood pressure; $\mathbf{d}$ inverse spoon-shaped blood pressure

Table 1 Comparison of ABPM between $\mathrm{OHT}$ group and control group $(\bar{\chi} \pm \mathrm{s}, \mathrm{mmHg})$

\begin{tabular}{lllllllll}
\hline Group & $\begin{array}{l}\text { 24 h mean } \\
\text { SBP }\end{array}$ & $\begin{array}{l}\text { 24 h mean } \\
\text { DBP }\end{array}$ & $\begin{array}{l}\text { Daytime } \\
\text { mean SBP }\end{array}$ & $\begin{array}{l}\text { Daytime } \\
\text { mean DBP }\end{array}$ & $\begin{array}{l}\text { Nocturnal } \\
\text { mean SBP }\end{array}$ & $\begin{array}{l}\text { Nocturnal } \\
\text { mean DBP }\end{array}$ & $\begin{array}{l}\text { SBP } \\
\text { circadian } \\
\text { difference }\end{array}$ & $\begin{array}{l}\text { DBP } \\
\text { circadian } \\
\text { difference }\end{array}$ \\
\hline $\begin{array}{l}\text { OHT } \\
(n=40)\end{array}$ & $107.2 \pm 8.4$ & $58.8 \pm 6.1$ & $11.2 \pm 8.9$ & $63.2 \pm 7.0$ & $101.8 \pm 7.8$ & $52.7 \pm 5.7$ & $8.4 \pm 4.7$ & $16.4 \pm 7.1$ \\
$\begin{array}{c}C o n t r o l \\
(n=40)\end{array}$ & $106.0 \pm 8.6$ & $58.2 \pm 4.8$ & $111.0 \pm 9.2$ & $63.2 \pm 6.2$ & $100.1 \pm 8.4$ & $52.2 \pm 4.4$ & $11.4 \pm 3.1$ & $16.9 \pm 6.3$ \\
$t \quad$ & 0.607 & 0.488 & 0.124 & 0.034 & 0.936 & 0.396 & -3.391 & -0.363 \\
$P$ & 0.595 & 0.218 & 0.735 & 0.702 & 0.724 & 0.129 & 0.033 & 0.409 \\
\hline
\end{tabular}

$B P$ blood pressure, $S B P$ systolic blood pressure, $D B P$ diastolic blood pressure

in age and sex between the two groups $(\mathrm{P}=0.081$ and 0.822 , respectively), as shown in Table 1 and Fig. 2. In addition, the primary clinical symptoms of the identified patients in OHT group included cardiovascular system, nervous system, and digestive system, as shown in Table 2. With respect to the common inducing factors that might resulted in OHT, the authors summarized them in this section, including prolonged standing, exercise, posture change, nervousness, prolonged sitting, muggy circumstance, other triggers, as shown in Fig. 3.

\section{Parameter comparison of blood pressure between research group and control group}

As shown in Table 3, the average systolic BP and diastolic BP in the OHT group at $24 \mathrm{~h}$, in the daytime, and in the nighttime were slightly higher than those in the control group, but the difference was not statistically significant $(\mathrm{P}>0.05)$. In addition, the difference of systolic BP between day and night in the control group was higher than that of the OHT group $(\mathrm{P}=0.033)$, and the difference of diastolic $\mathrm{BP}$ between day and night in the control group was slightly higher than that of the $\mathrm{OHT}$ group $(\mathrm{P}=0.409)$. 

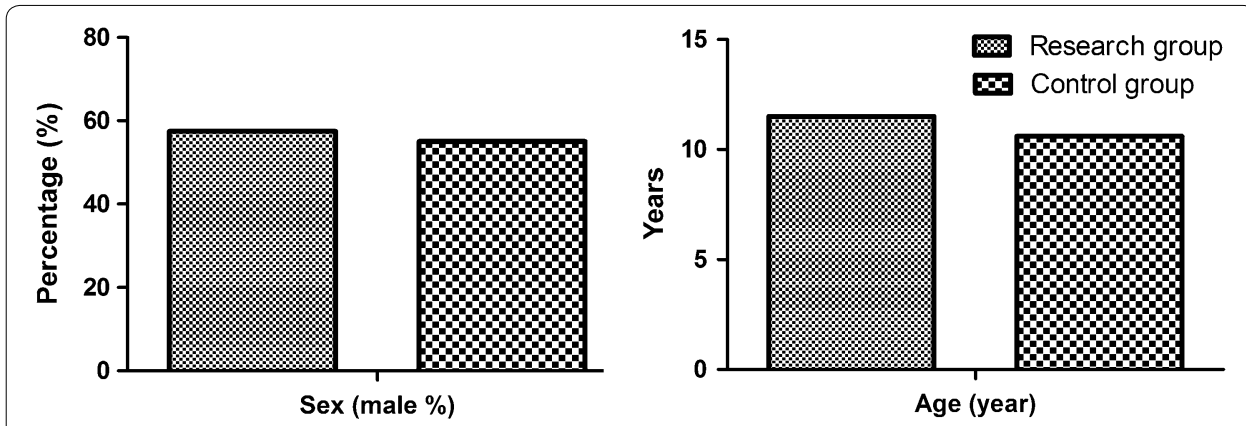

Fig. 2 General characteristics of the identified patients

Table 2 Comparison of heart rate variability between research group and control group

\begin{tabular}{lcccc}
\hline Indicator & Control group & Research group & t & P \\
\hline SDNN (ms) & $121.31 \pm 32.54$ & $154.23 \pm 9.56$ & 3.795 & 0.000 \\
SDANN (ms) & $122.96 \pm 5.40$ & $142.68 \pm 3.21$ & 4.127 & 0.002 \\
rMSSD (ms) & $76.08 \pm 3.21$ & $77.52 \pm 3.62$ & 1.238 & 0.301 \\
pNN50 (\%) & $26.30 \pm 4.52$ & $27.51 \pm 2.36$ & 1.542 & 0.181 \\
CV & $0.12 \pm 0.000$ & $0.12 \pm 0.000$ & 0.310 & 0.823 \\
TP & $9532.21 \pm 452.13$ & $12,311.25 \pm 411.23$ & 3.421 & 0.001 \\
ULF & $4231.10 \pm 369.21$ & $6987.48 \pm 398.41$ & 4.259 & 0.000 \\
VLF & $2896.41 \pm 231.41$ & $3961.80 \pm 357.12$ & 2.361 & 0.010 \\
\hline
\end{tabular}

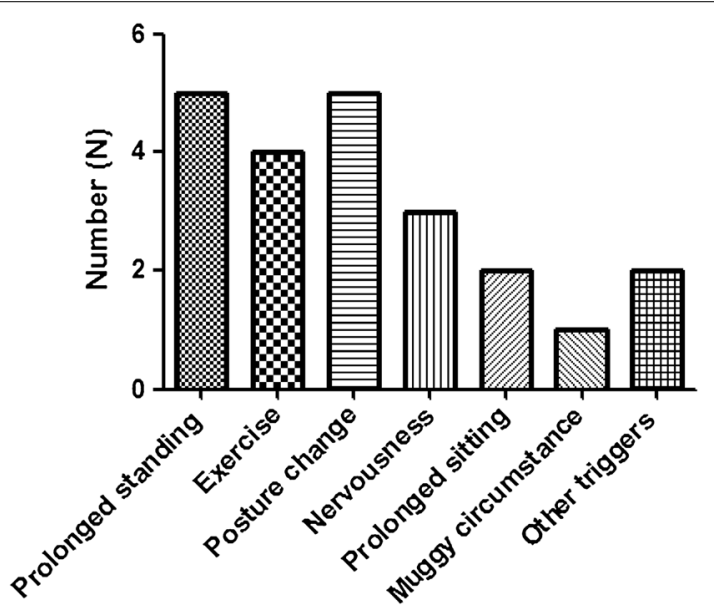

Fig. 3 Common inducing factors that might resulted in $\mathrm{OHT}$

\section{Comparison of blood pressure types between research group and control group}

In the OHT group, non-dipper BP accounted for $72.5 \%$ (29/40 cases), and dipper BP accounted for $27.5 \%$ (11/40 cases). On the contrary, the non-dipper BP accounted for $45.0 \%$ (18/40 cases), and dipper BP accounted for $55.0 \%$ (22/40 cases). The BP difference between the two groups was statistically significant $\left(X^{2}=6.600, P=0.012\right)$. No over spoon-shaped BP and inverse spoon-shaped BP could be observed in both OHT and control groups, as shown in Table 4 and Fig. 4. 
Table 3 Comparison of heart rate variability between boy and girl in research group

\begin{tabular}{lcccc}
\hline Indicator & Boy group & Girl group & t & P \\
\hline Age (year) & $12.01 \pm 0.31$ & $12.89 \pm 0.28$ & 1.891 & 0.089 \\
SDNN (ms) & $155.30 \pm 3.21$ & $142.58 \pm 3.48$ & 3.008 & 0.003 \\
SDANN (ms) & $148.21 \pm 3.86$ & $139.11 \pm 4.50$ & 0.956 & 0.451 \\
rMSSD (ms) & $79.55 \pm 3.85$ & $78.21 \pm 3.69$ & 0.781 & 0.487 \\
pNN50 (\%) & $31.25 \pm 1.26$ & $29.91 \pm 1.69$ & 1.112 & 0.361 \\
CV & $0.11 \pm 0.00$ & $0.10 \pm 0.00$ & 1.460 & 0.189 \\
TP & $11,231.12 \pm 445.21$ & $1023.15 \pm 397.13$ & 3.921 & 0.002 \\
ULF & $6541.20 \pm 451.23$ & $4895.27 \pm 401.23$ & 2.361 & 0.002 \\
VLF & $3789.40 \pm 230.78$ & $2891.47 \pm 309.87$ & 3.561 & 0.001 \\
\hline
\end{tabular}

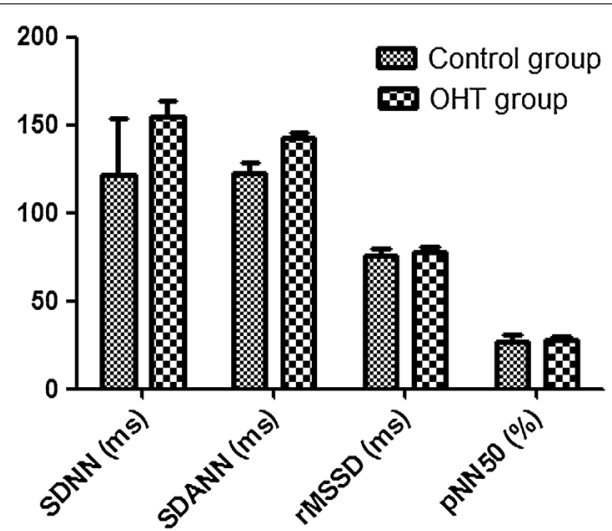

Fig. 4 Comparison of heart rate variability between research group and control group

\section{Comparison of heart rate variability between research group and control group}

AS shown in Table 2, the time domain SDNN and SDANN in the OHT group were higher than those in the control group $(\mathrm{P}<0.01)$. In addition, the indicators including TP, ULF, VLF, and LF/HF were higher in the OHT group, when compared with control group $(\mathrm{P}<0.01)$. In addition, in terms of subgroup analysis within the OHT group, the results were illustrated in Table 3. First of all, the age difference between boys and girls was not statistically significant $(\mathrm{P}>0.05)$. When compared with girls,

Table 4 Comparison of heart rate variability between research group and control group

\begin{tabular}{lcccc}
\hline Indicator & Control group & Research group & t & P \\
\hline SDNN (ms) & $121.31 \pm 32.54$ & $154.23 \pm 9.56$ & 3.795 & 0.000 \\
SDANN (ms) & $122.96 \pm 5.40$ & $142.68 \pm 3.21$ & 4.127 & 0.002 \\
rMSSD (ms) & $76.08 \pm 3.21$ & $77.52 \pm 3.62$ & 1.238 & 0.301 \\
pNN50 (\%) & $26.30 \pm 4.52$ & $27.51 \pm 2.36$ & 1.542 & 0.181 \\
CV & $0.12 \pm 0.000$ & $0.12 \pm 0.000$ & 0.310 & 0.823 \\
TP & $9532.21 \pm 452.13$ & $12,311.25 \pm 411.23$ & 3.421 & 0.001 \\
ULF & $4231.10 \pm 369.21$ & $6987.48 \pm 398.41$ & 4.259 & 0.000 \\
VLF & $2896.41 \pm 231.41$ & $3961.80 \pm 357.12$ & 2.361 & 0.010 \\
\hline
\end{tabular}


Table 5 Comparison of heart rate variability between boy and girl in research group

\begin{tabular}{lcccc}
\hline Indicator & \multicolumn{1}{c}{ Boy group } & \multicolumn{1}{c}{ Girl group } & t & P \\
\hline Age (year) & $12.01 \pm 0.31$ & $12.89 \pm 0.28$ & 1.891 & 0.089 \\
SDNN (ms) & $155.30 \pm 3.21$ & $142.58 \pm 3.48$ & 3.008 & 0.003 \\
SDANN (ms) & $148.21 \pm 3.86$ & $139.11 \pm 4.50$ & 0.956 & 0.451 \\
rMSSD (ms) & $79.55 \pm 3.85$ & $78.21 \pm 3.69$ & 0.781 & 0.487 \\
pNN50 (\%) & $31.25 \pm 1.26$ & $29.91 \pm 1.69$ & 1.112 & 0.361 \\
CV & $0.11 \pm 0.00$ & $0.10 \pm 0.00$ & 1.460 & 0.189 \\
TP & $11,231.12 \pm 445.21$ & $1023.15 \pm 397.13$ & 3.921 & 0.002 \\
ULF & $6541.20 \pm 451.23$ & $4895.27 \pm 401.23$ & 2.361 & 0.002 \\
VLF & $3789.40 \pm 230.78$ & $2891.47 \pm 309.87$ & 3.561 & 0.001 \\
\hline
\end{tabular}

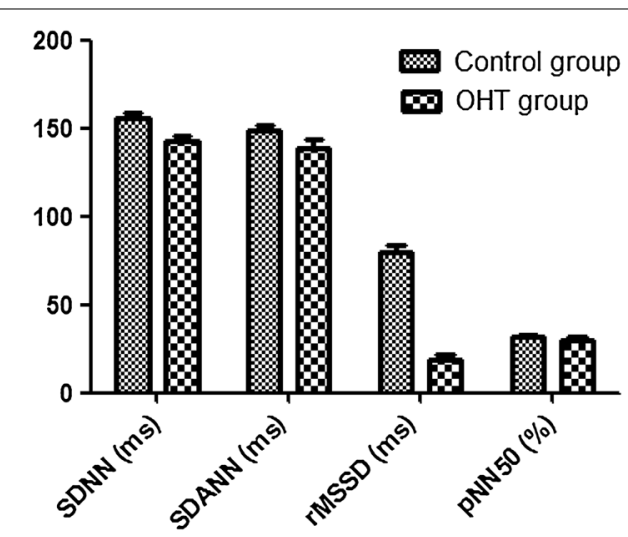

Fig. 5 Comparison of heart rate variability between boy and girl in research group

the time domain SDNN increased $(\mathrm{P}=0.003)$, and the frequency index TP, ULF, and VLF increased in boy group $(\mathrm{P}<0.05)$, as shown in Table 5 and Fig. 5.

\section{Discussion}

Perhaps on account of overcompensation for the gravitational challenge, the BP may rise when standing. In clinical practice, this phenomenon is called OHT, which is drawing increasing attention in recent years. It has been found to be associated with more prominent hypertensive target organ damage, such as silent cerebrovascular lesions. As mentioned above, no consensus has been reached on the definition of OHT, but OHT can be defined as a drop of SBP $\leq 20 \mathrm{mmHg}$ and/or DBP $\leq 10 \mathrm{mmHg}$ at orthostasis, according to the American Academy of Neurology. On the basis of our clinical experience, OHT is a common and disturbing problem and is especially prevalent among hospitalized patients. In addition, as a common clinical finding, it is closely associated with an increased risk of cardiovascular mortality, and is also an established marker for cardiovascular risk in patients with hypertension in the general population.

Arterial BP in the human body keeps changing along with blood flow, and there is a significant circadian rhythm in general. In terms of physiological basis, sympathetic 
nerves predominate during daytime in normal children, which enhances the concentration of catecholamines in plasma. The vagus nerve predominates during sleep at night, and the concentration of catecholamines in blood decreases. In further, when the body is in a supine position during sleep, redistribution of systemic blood flow occurs, and a large amount of blood concentrates in the lower limbs, which subsequently increase blood flow to the center, increased central venous pressure, increase afferent impulses in baroreceptors, and increase inhibitory stimulation of afferent vasomotor centers. Afterwards, the sympathetic excitatory reflex is weakened, the cardiac output decreases when the heart negatively inverts, and then the peripheral vascular resistance decreases and the whole body muscle relaxes, which subsequently results in lower BP levels during the night than during the day.

The circadian rhythm of blood pressure is one of the most important features of the human body. Maintaining a normal circadian rhythm of blood pressure is of great significance for protecting vital organs such as heart, liver and kidney, etc. For normal children, nocturnal BP is lower than daytime BP. Through the BP curve, BP is at its lowest point between $0-3$ at early morning, starts to rise at $4-5$ in the morning, and peaks between 6 and 8 in the morning. Afterwards, the BP is gradually steady, peaks again at 4-6 in the afternoon, and then slowly decreases. The BP throughout $24 \mathrm{~h}$ is presented as "long spoon-shaped curve" with double peaks and one valley. The semiautomatic ambulatory blood pressure monitoring can better reflect the BP fluctuation and circadian rhythm. The "over spoon-shaped" BP is often accompanied by OHT, and the "inverse spoon-shaped" BP is related to continuous sympathetic nerve stimulation, often accompanied by OHT [20]. Our team is dedicated to investigating the ambulatory BP changes in children with OHT and vasovagal syncope, and the corresponding results demonstrated that the BP type in children with OHT is mostly nondipper BP and is associated with autonomic dysfunction [21]. In this study, the data illustrated that the most frequent BP type was non-dipper BP in children with OHT, which is consistent with the findings of Moriguchi et al. [22]. Wu et al. attempted to investigate the prevalence of hypertension in adults and its related factors $(n=1638)$, and they put forward the idea that OHT risk was closely related to changes of systolic BP during postural changes [23]. In this study, 80 cases were identified, and they received semiautomatic ambulatory blood pressure monitoring afterwards. The data demonstrated that the average BP in the OHT group was slightly higher than that in the control group, but the difference was not statistically significant. After comparisons between the two groups, it could be claimed that the pathogenetic mechanism of OHT, such as increased sympathetic activity and increased adrenaline boost sensitivity, could result in the increased BP in children with OHT, when compared with healthy children.

\section{Conclusion}

In summary, the data in this research revealed that the BP type in children with OHT was mainly non-dipper BP, and the healthy children in the control group were mainly spoon-type BP. The difference between the two groups was statistically significant $(\mathrm{P}<0.05)$. Additionally, the difference of systolic BP between day and night in the 
control group was greater than in the OHT group $(\mathrm{P}<0.05)$. In brief, on account of autonomic dysfunction, the BP type in children with OHT was mostly non-dipper BP, and the circadian rhythm of BP disappeared.

\section{Authors' contributions}

Study design: YZ and LD. Literature review: YZ, WC, XJ, GB, and XM. Research performance: YZ, WC, XJ, GB, and XM. Gave advice for setup: LD. Data checking: XJ, GB, and XM. All authors read and approved the final manuscript.

\section{Author details}

${ }^{1}$ Department of Pediatrics, Lixian People's Hospital in Hunan, Lixian 415500, China. ${ }^{2}$ Department of Pediatric Cardiovasology, Children's Medical Center, The Second Xiangya Hospital of Central South University, Institute of Pediatrics of Central South University, Changsha 410011, China.

\section{Competing interests}

The authors declare that they have no competing interests.

\section{Availability of data and materials}

The relevant data and materials involved in this research is availabled.

\section{Consent for publication}

If this paper can be accepted, we also agree to transfer the copyright.

\section{Ethical approval and informed consent}

The study was approved by the Medical Ethics Committee of the Second Xiangya Hospital of Central South University. All informed consent was obtained from the subject's or guardian before the 24-h semiautomatic ambulatory blood pressure monitoring examination.

\section{Financial support}

National Science-technology Support Plan Projects (Grant No. 2012BAI03B03), Natural Science Foundation of Hunan Proince, China (Grant No. 13JJ5014), Natural Science Foundation Supported by the Hunan Provincial Department of Health (Grant No. B2013-013)

\section{Publisher's Note}

Springer Nature remains neutral with regard to jurisdictional claims in published maps and institutional affiliations.

Received: 29 May 2018 Accepted: 10 July 2018

Published online: 25 September 2018

\section{References}

1. Kario K. Orthostatic hypertension-a new haemodynamic cardiovascular risk factor. Nat Rev Nephrol. 2013;9(12):726-38.

2. Kario K. Orthostatic hypertension: a measure of blood pressure variation for predicting cardiovascular risk. Circ J. 2009;73(6):1002-7.

3. Fessel J, Robertson D. Orthostatic hypertension: when pressor reflexes overcompensate. Nat Clin Pract Nephrol. 2006;2(8):424-31.

4. Bhuachalla BN, McGarrigle CA, O'Leary N, et al. Orthostatic hypertension as a risk factor for age-related macular degeneration: evidence from the Irish longitudinal study on ageing. Exp Gerontol. 2018;106:80-7.

5. Bursztyn M, Jacobs JM, Hammerman-Rozenberg A, et al. Prevalence of orthostatic hypertension in the very elderly and its relationship to all-cause mortality. J Hypertens. 2016;34(10):2053-8.

6. Fan $\mathrm{XH}$, Sun $\mathrm{K}$, Zhou XL, et al. Association of orthostatic hypertension and hypotension with target organ damage in middle and old-aged hypertensive patients. Natl Med J China. 2011;91(4):220-4

7. Rutan GH, Hermanson B, Bild DE, et al. Orthostatic hypotension in older adults. The Cardiovascular Health Study. CHS Collaborative Research Group. Hypertension. 1992;19(6 Pt 1):508-19.

8. Wang LL, Liu ZD, Zhao YY, et al. Postural change in blood pressure in old-aged hypertensive patients and effects on neurocognitive disorder. J Clin Exp Med. 2012;11(4):241-2.

9. Zhao J, Yang JY, Jin HF, et al. Clinical analysis of orthostatic hypertension in children. Chin J Pediatr. 2012;50(11):839-42.

10. Kang MH, Xu Y, Wang C, et al. Differences of age and gender in children with orthostatic hypertension. Chin J Appl Chin Pediatr. 2013;28(1):24-6.

11. Liu DY, Xiang JB, Wang C. Research progress on orthostatic hypertension. Chin J Pract Pediatr. 2014;29(6):471-6.

12. Norcliffe-kaufmann L, Kaufmann $\mathrm{H}$. Is ambulatory blood pressure monitoring useful in patients with chronic autonomic failure. Clin Auton Res. 2014;24(4):189-92.

13. Flynn JT, Daniels SR, Hayman LL, et al. Update: ambulatory blood pressure monitoring in children and adolescents: a scientific statement from the American Heart Association. Hypertension. 2014;63(5):1116-35.

14. The Subspecialty Group of Cardiology, The Society of Pediatrics, Chinese Medical Association, The Editorial Board, Chinese Journal of Pediatrics. Guidelines for diagnosis of syncope in children. Chin J Pediatr. 2009:47(2):99-101.

15. $X u Y$, Lin $P$, Wang $C$, et al. Investigation of $24-h$ blood pressure monitoring for evaluating treatment outcome of nerve-mediated syncope in children. Chin J Contemp Pediatr. 2013;15(5):458-61. 
16. Soergel M, Kirschstein M, Busch C, et al. Oscillometric 24-h ambulatory blood pressure values in healthy children and adolescents: a multicenter trial including 1141 subjects. J Pediatr. 1997;130(2):178-84.

17. Zhang KZ, Guo JH, Liu HY, et al. Clinical electrocardiography. Changsha: Hunan Science and Technology Press; 2002. p. 1354.

18. Yang XH, Lu XZ. Adolescent ambulatory blood pressure monitoring. Chin J Hypertens. 2009;17(7):667-9.

19. Tan J, Zhang YY. The mechanism and prevention of postural hypertension. Chin J Pract Intern Med. 2012;32(1):32-5.

20. Xu Y, Kang MH, Wang C. Orthostatic hypertension in children. Chin J Appl Chin Pediatr. 2013;28(13):964-7.

21. Liu DY, Xiang JB, Lin P, et al. 24-h ambulatory blood pressure changes in children with orthostatic hypertension. Chin J Appl Chin Pediatr. 2014;29(22):1731-3.

22. Moriguchi A, Nakagami H, Kotani $\mathrm{N}$, et al. Contribution of cardiovascular hypersensitivity to orthostatic hypertension and the extreme dipper phenomenon. Hypertens Res. 2000;23(2):119-23.

23. Wu JS, Yang YC, Lu FH, et al. Population-based study on the prevalence and correlates of orthostatic hypotension/ hypertension and orthostatic dizziness. Hypertens Res. 2008;31(5):897-904.

Ready to submit your research? Choose BMC and benefit from:

- fast, convenient online submission

- thorough peer review by experienced researchers in your field

- rapid publication on acceptance

- support for research data, including large and complex data types

- gold Open Access which fosters wider collaboration and increased citations

- maximum visibility for your research: over 100M website views per year

At BMC, research is always in progress.

Learn more biomedcentral.com/submissions 